International Journal of Management, IT \& Engineering

Vol. 11 Issue 06, June 2021

ISSN: 2249-0558 Impact Factor: 7.119

Journal Homepage: http://www.ijmra.us, Email: editorijmie@gmail.com

Double-Blind Peer Reviewed Refereed Open Access International Journal - Included in the International Serial Directories Indexed \& Listed at:

Ulrich's Periodicals Directory @, U.S.A., Open J-Gate as well as in Cabell's Directories of Publishing Opportunities, U.S.A

\title{
Investigating the determinants of successful budgeting with SVM and Binary models
}

\author{
Naveen Kunnathuvalappil Hariharan \\ Sr. Hyperion SME \& Department of Information Technology, United States
}

June 2021

\begin{abstract}
Learning the determinants of successful project budgeting is crucial. This research attempts to empirically find the determinants of a successful budget. To find this, this work applied three different supervised machine learning algorithms for classification: Support Vector Machine (SVM), Logistic regression, and Probit regression with data from 470 projects. Five features have been selected: coordination, participation, budget control, communication, and motivation. The SVM analysis results showed that SVM could predict successful and failed budgets with fairly good accuracy. The results from Logistic and Probit regression showed that if managers properly focus on coordination, participation, budget control, and communication, the probability of success in project-budget increases.

Keywords: Budgeting, Support Vector Machine, Probit regression, algorithms
\end{abstract}

\section{Introduction}

A project's budget is the amount of money set aside for the project's specific objective over a set period of time. Budget management's goal is to keep project expenditures within the allocated budget while meeting the project's objectives. A successful project is one that satisfies four success criteria: the project's scope is completed on time, within budget, and, once done, it meets the donor and beneficiary quality expectations. To be genuinely successful, project managers must focus on satisfying all of those requirements (Callahan, Stetz, and Brooks 2011).

The fact is that most project managers tend to focus the majority of their efforts on keeping the project on track. They spend the majority of their time organizing and controlling the timetable and often overlook budget monitoring and management.

Project budgeting is frequently done in tandem with the establishment of the project schedule during the early stages of project planning. Both the projected lengths of jobs and the resources are given to the project influence the procedures involved in budgeting. Budgeting is a control tool that allows you to evaluate and measure actual expenditures against the budget. In the execution of a project, the budget is frequently a pretty fixed parameter (Taylor 2003). When a schedule starts to slip, the cost is affected accordingly. When project expenses start to rise, the project manager should review the Project Plan to see if the scope, budget, or schedule have to be changed.

The applicable cost elements connected with project tasks are determined in order to build the budget. Each task's cost development should be straightforward and direct, consisting of labor, 
material, and other direct costs. The cost of completing work is proportional to the number of people assigned to it, the length of time it takes to complete it, and the expense of any nonlabor things it necessitates (Shim, Siegel, and Shim 2011).

The project manager is in charge of calculating the budget needed to accomplish the project's activities. All project costs, including internally and externally located human resources, materials, and supplies, should be allocated to project activities, and all elements of the project, such as the expense of internal and external human capital, equipment, travel, materials, and supplies, should be accounted for. The budget should be far more precise and accurate than the one included in the project proposal. If a project manager begins her employment with a contract budget, she must analyze the assumptions established during the project proposal phase and ensure that the agreed-upon scope can be completed within the contract budget (Roberts 2011).

To create the budget estimate, the Project Manager can employ either manual or automated technologies. Simple spreadsheets or complicated budget estimating programs are examples of budgeting tools. The Project Manager should keep records on how this budget was established for historical purposes and allow the budget to be revised. Checklists for cost estimates help confirm that all initial budgeting information is available and that all bases are covered. The Project Manager also should budget for the cost of human resources as well as the equipment and supplies needed to complete the work (White and Fortune 2002). The strategy for acquiring employees and products for the project will have a direct impact on the budgeting process. A variety of financial, social, and organizational restrictions may govern the methods used to obtain resources such as persons, equipment, services, and materials. Existing resource acquisition rules, guidelines, and procedures must be known to the Project Manager. Furthermore, acquisition decisions may be influenced by the preferences of beneficiaries and/or donor representatives. Budgeting tactics that were effective and applicable in previous projects can be utilized to obtain an insight into budgeting techniques; those that were effective and applicable in previous projects can be regarded for implementation in the current project (Harrison and Lock 2017).

The budget management includes a tentative payout schedule as well as a description of how spending will be handled. The budget management plan should, for example, explain the accounting, spending verification, and purchasing payment procedures (Blomquist, Newsome, and Brad Stone 2003). Depending on the demands of the project stakeholders, the plan could be formal or informal. The budget management strategy can include purchase permission levels, donor requirements, and donor-approved charges. 


\section{Determinants}

\section{Coordination of budget-related activities}

Coordination is the process of establishing the framework within which budget actions will be carried out. The systematization of interdependent pieces into a single unit is referred to as coordination. Coordination entails combining an organization's multiple functional parts into a unified structure and delegating authority and responsibility to individuals. Integrity, openness, consistency, justice, and a professional approach should guide the adoption of budget structures and processes. Budget coordination is an endeavor to get employees to work together for the greater interest of the company (Binkele-Raible and Fernau 2010).

\section{Participation of employees in the budgeting process}

There are two ways to participate in the budgeting process. On the one hand, employees are involved in the budgeting process. Employees, on the other hand, have a say in which budget option is chosen. Self-imposed budgeting is a participatory approach to budgeting that allows all stakeholders to participate in the development of a budget. During this activity, difficult conversations take place in order to arrive at the most advantageous budget. To assuage fears and anxieties typically connected with budgeting, the negotiation should be conducted in an open and fair manner (Wong-On-Wing, Guo, and Lui 2010)(Parker and Kyj 2006).

\section{Communication}

A successful budgeting process necessitates the communication of budget plans, which improves the efficiency with which the budgeting process is carried out. All senior managers from diverse functions should be involved in developing the plan. Leading and lagging indicators for budget plans are identified through continual communication among budget holders, and then conveyed to all employees and stakeholders in the organization. Overall, the communication process is critical for fostering a sense of collaboration and ensuring that all important participants are aware of their roles in meeting budget objectives (Greenberg 2006).

\section{Employee motivation}

Budget targets should not be set at unnecessarily high or low levels since this will simply lead to a lack of drive or enable too much slack. If there is room in the budget for slack, waste will occur. As a result, establishing budget targets necessitates the engagement of all stakeholders. Employees must fully understand and support a budget in order for it to be successful. If lower or middle management perceives top management's attitude toward budgeting to be negative, or if top management merely accepts budgeting as a necessary sacrifice, then their own attitude toward budgeting will reflect a similar lack of excitement (Wong-On-Wing, Guo, and Lui 2010; Rickards 2006). 


\section{Budget control}

Budget control is defined as trying to compare the actual budget to the projected budget and taking corrective action if major differences exist. Corrective actions, on the other hand, are not needed if the assessment reveals that the actual results are consistent with the budgeted figures or if the variance amount is favorable. Budget control is carried out to increase budget holders' financial accountability and the financial viability of organizations (Hofstede 1970; Ahrens, Ferry, and Khalifa 2018).

\section{Support Vector Machine (SVM)}

\section{Methodology}

SVM classification's fundamental goal is to effectively divide classes based on a collection of features. We may illustrate this with a straightforward two-class problem, as seen in Figure 1. To the left is the simplest scenario, in which the classes are separable linearly (Noble 2006). By maximizing the distance between the nearest elements in each class, the SVM algorithm divides them. Support vectors are the closest elements of each class on either side of the line (Ukil 2007).
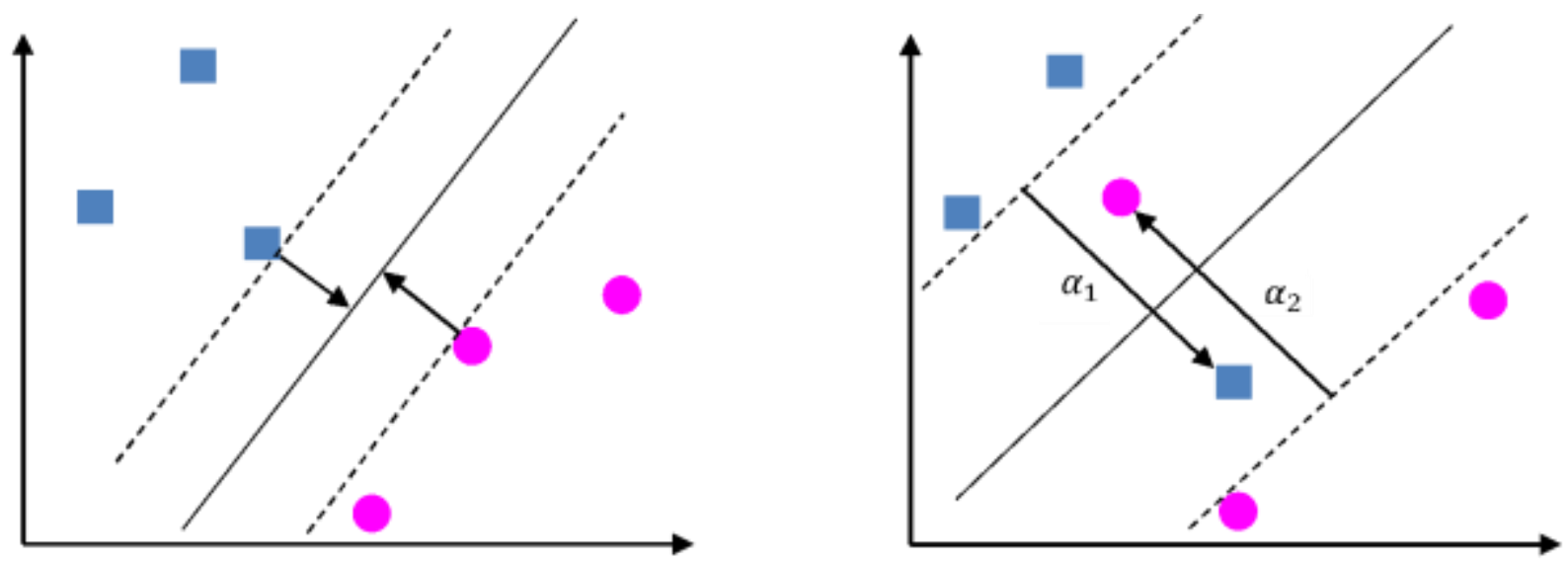

\section{Figure 1 Simple 2-class support vector machine}

\section{Binary models}

The dependent variable in this class of models can take on only two possible values. Y could be a dummy variable indicating the likelihood of a case occurring or a choice between two possibilities. For instance, the outcomes of each match in a league sample may be useful in modeling (whether won or not). The teams differ in a variety of quantifiable characteristics, which we refer to as $\mathrm{x}$. The purpose is to measure the relationship between team characteristics and the probability of winning a game. $\mathrm{y}$ is a binary variable with a range of 0 to 1 . It is 


\section{International Journal of Management, IT \& Engineering}

Vol. 11 Issue 06, June 2021

ISSN: 2249-0558 Impact Factor: 7.119

Journal Homepage: http://www.ijmra.us, Email: editorijmie@gmail.com

Double-Blind Peer Reviewed Refereed Open Access International Journal - Included in the International Serial Directories Indexed \& Listed at: Ulrich's Periodicals Directory @, U.S.A., Open J-Gate as well as in Cabell's Directories of Publishing Opportunities, U.S.A

insufficient to merely quite nearly regress $\mathrm{y}$ on $\mathrm{x}$, because the inferred model of the conditional average imposes insufficient constraints on the model's residuals. Additionally, in a simple linear regression, the value of $y$ is not limited to zero. Rather than that, we use a specification to address the fundamental requirements of binary regressors (Caesarendra, Widodo, and Yang 2010; Zhu and Hastie 2005). Assume we represent the probability of observing 1 as:

$$
\operatorname{Pr}\left(y_{i}=1 \mid x_{i}, \beta\right)=1-F\left(-x_{i}^{\prime} \beta\right),
$$

Where $\mathrm{F}$ is a pure growing continuous function that accepts a true value and returns a value between zero and one, the kind of binary model that is chosen is defined by the function F. As a result:

$$
\operatorname{Pr}\left(y_{i}=0 \mid x_{i}, \beta\right)=F\left(-x_{i}^{\prime} \beta\right) .
$$

Given such a specification, we can utilize the maximum likelihood method to estimate the values of this model. The likelihoods function is denoted by the following:

$$
l(\beta)=\sum_{i=0}^{n} y_{i} \log \left(1-F\left(-x_{i}^{\prime} \beta\right)\right)+\left(1-y_{i}\right) \log \left(F\left(-x_{i}^{\prime} \beta\right)\right) .
$$

Due to the nonlinear nature of first-order conditions for this probability, an iterative solution is required to generate parameter estimates. This standard has two opposing viewpoints worth examining. To begin, binary models are frequently employed to specify latent variables. Assume that there is an unobserved latent variable $\mathrm{y}^{*}$ that is linearly connected to $\mathrm{x}$.

$$
y_{i}^{*}=x_{i}^{\prime} \beta+u_{i}
$$

Where $\mathrm{u}$ denotes random fluctuations, $\mathrm{y}^{*}$ controls whether the measured dependent variable achieves a predetermined value:

$$
y_{i}= \begin{cases}1 & \text { if } y_{i}^{*}>0 \\ 0 & \text { if } y_{i}{ }^{*} \leq 0 .\end{cases}
$$

In this case, the threshold is reduced to 0 , but the value of the threshold is irrelevant as long as $\mathrm{x}$ has a constant term (Musa 2013). The marginal impact of a feature $\mathrm{x}$ factor on a single conditional probability associated with the target $y$ is computed as follows:

$$
\frac{\partial \mathrm{E}\left(y_{i} \mid x_{i}, \beta\right)}{\partial x_{i j}}=f\left(-x_{i}^{\prime} \beta\right) \beta_{j} \text {. }
$$

The Budget success $=1$, if the budget is successful. Budget success $=0$ if it is failed. The data of http://www.ijmra.us, Email: editorijmie@gmail.com 


\section{International Journal of Management, IT \& Engineering}

Vol. 11 Issue 06, June 2021

ISSN: 2249-0558 Impact Factor: 7.119

Journal Homepage: http://www.ijmra.us, Email: editorijmie@gmail.com

Double-Blind Peer Reviewed Refereed Open Access International Journal - Included in the International Serial Directories Indexed \& Listed at: Ulrich's Periodicals Directory @, U.S.A., Open J-Gate as well as in Cabell's Directories of Publishing Opportunities, U.S.A

other variables are PCA factors of different responses collected on the basis of 5 features. The data have been collected from Statista.

\section{Results}

\section{The shapes of relationships.}
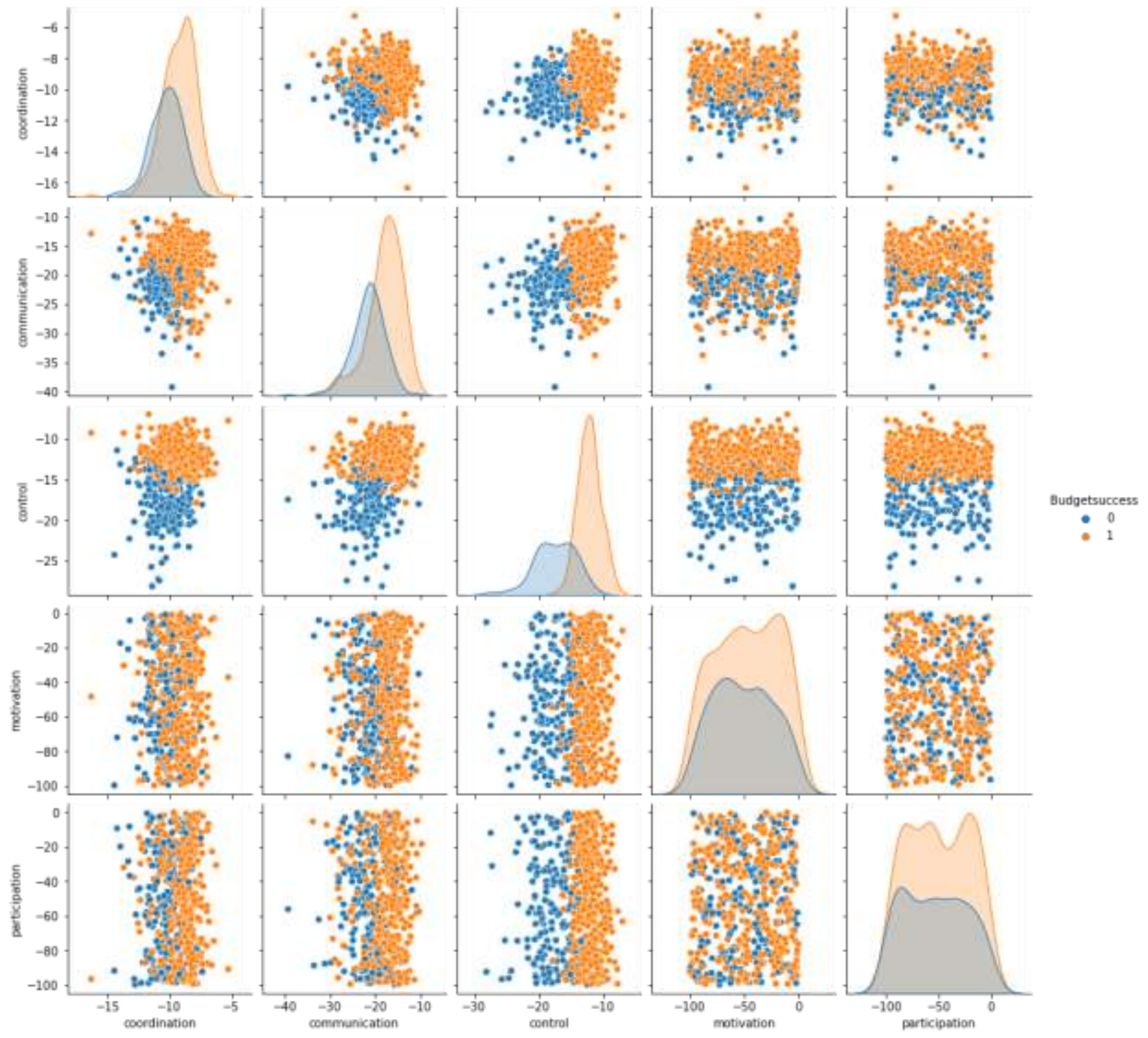

Figure 2. Pairplot of features 
International Journal of Management, IT \& Engineering

Vol. 11 Issue 06, June 2021

ISSN: 2249-0558 Impact Factor: 7.119

Journal Homepage: http://www.ijmra.us, Email: editorijmie@gmail.com

Double-Blind Peer Reviewed Refereed Open Access International Journal - Included in the International Serial Directories Indexed \& Listed at: Ulrich's Periodicals Directory @, U.S.A., Open J-Gate as well as in Cabell's Directories of Publishing Opportunities, U.S.A

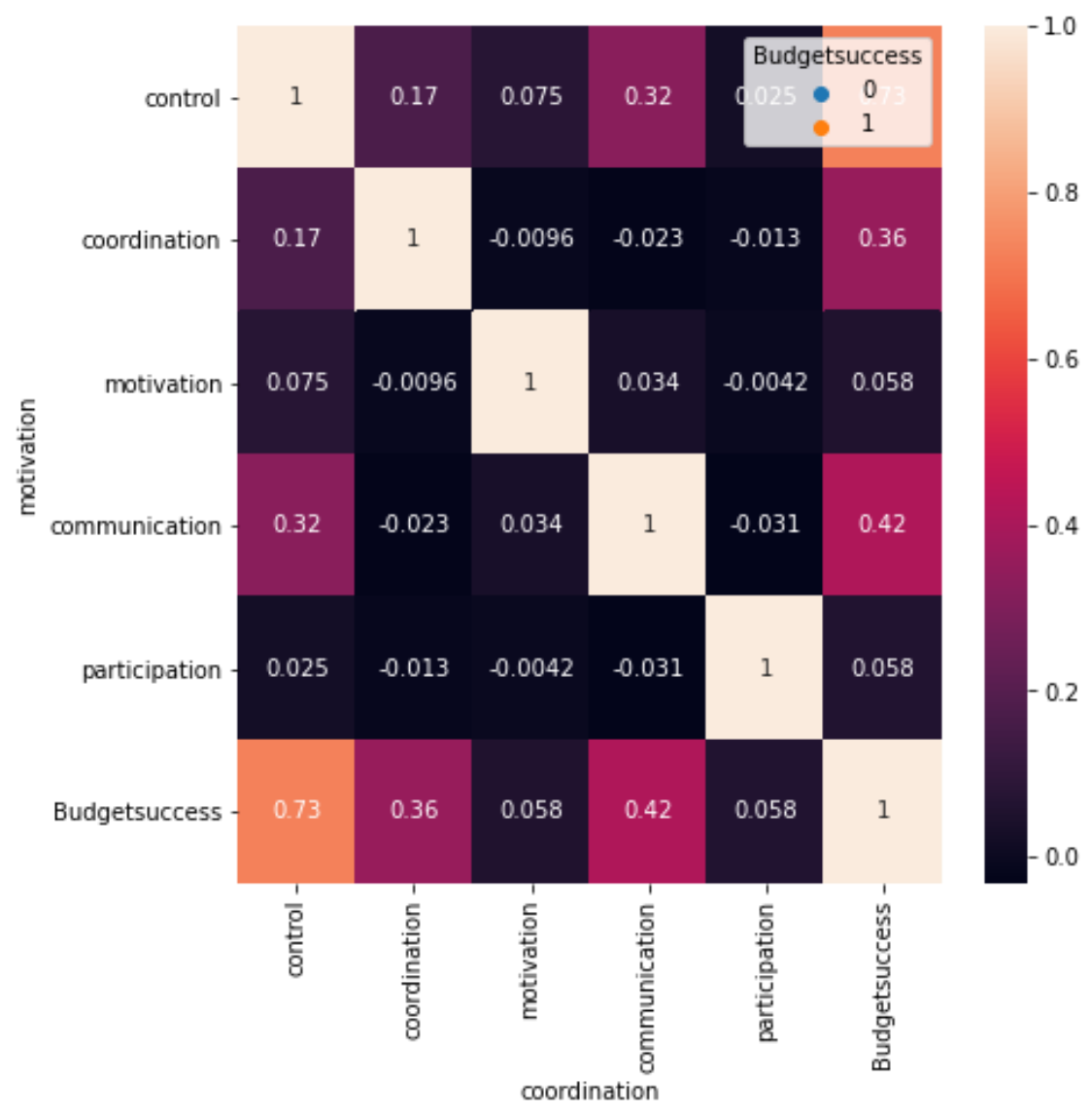

Figure 3. correlation among features and target

Figure 3 displays the correlation coefficients between features and budget success. The results show that budget success is correlated positively with control, coordination, motivation, communication, participation with coefficients of $0.73,0.36,0.058,0.42$, and 0.058 , respectively. This implies that these features are positive factors for the success of the budget. 
International Journal of Management, IT \& Engineering

Vol. 11 Issue 06, June 2021

ISSN: 2249-0558 Impact Factor: 7.119

Journal Homepage: http://www.ijmra.us, Email: editorijmie@gmail.com

Double-Blind Peer Reviewed Refereed Open Access International Journal - Included in the International Serial Directories Indexed \& Listed at: Ulrich's Periodicals Directory @, U.S.A., Open J-Gate as well as in Cabell's Directories of Publishing Opportunities, U.S.A

\section{Features Correlation}
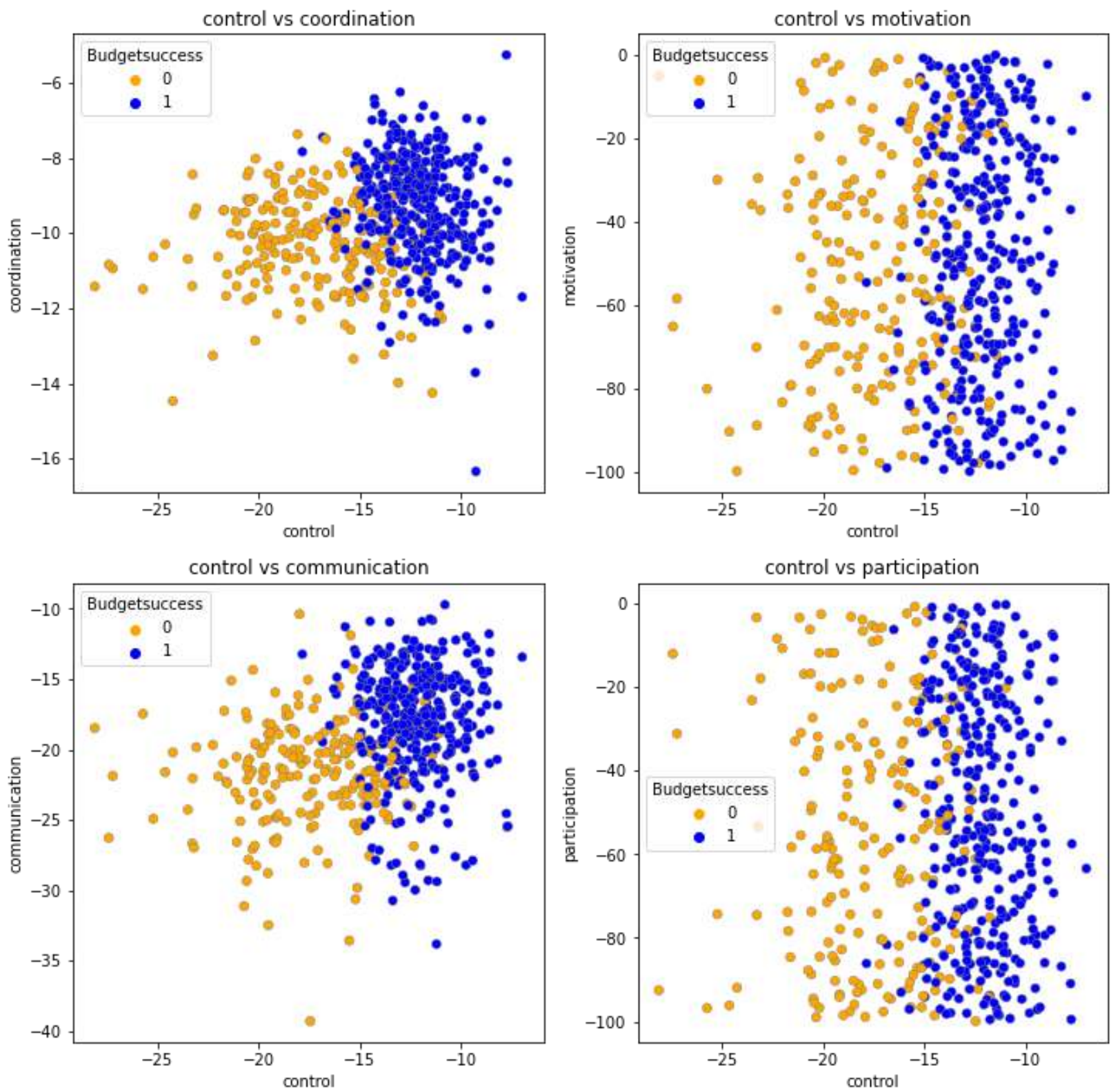

Figure 3. Features correlation 


\section{International Journal of Management, IT \& Engineering}

Vol. 11 Issue 06, June 2021

ISSN: 2249-0558 Impact Factor: 7.119

Journal Homepage: http://www.ijmra.us, Email: editorijmie@gmail.com

Double-Blind Peer Reviewed Refereed Open Access International Journal - Included in the International Serial Directories Indexed \& Listed at: Ulrich's Periodicals Directory @, U.S.A., Open J-Gate as well as in Cabell's Directories of Publishing Opportunities, U.S.A

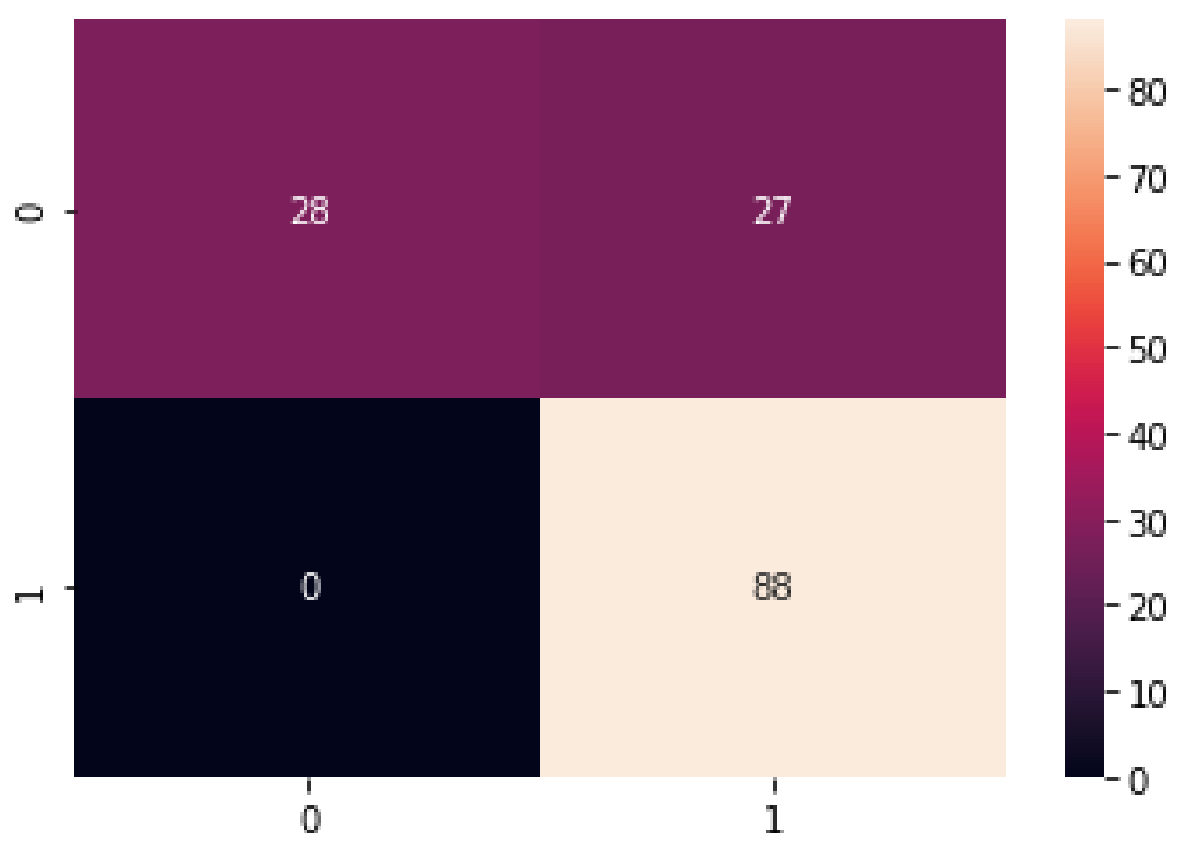

Figure 4 Confusion matrix

The result of the confusion matrix information is depicted in figure 4. Among the projects predicted to fail, none were classified as lacking budgets when they actually did (type one error). As a result, we discovered no type one error. Additionally, 28 of the predicted project budgets that failed to materialize were classified as successful (type two error). The classification report is shown in Table 1. This graph illustrates various estimations of the fiscore, precision, support, and recall values. Additionally, these scores indicate that the model is fairly accurate. In short, the SVM Model was fairly accurate in classifying projects as successful or unsuccessful.

Table 1. Classification report

precision recall f1-score support

$\begin{array}{lllll}0 & 1.00 & 0.51 & 0.67 & 55 \\ 1 & 0.77 & 1.00 & 0.87 & 88\end{array}$

\begin{tabular}{ccccc} 
accuracy & \multicolumn{3}{c}{0.81} & \multicolumn{2}{c}{143} \\
macro avg & 0.88 & 0.75 & 0.77 & 143 \\
weighted avg & 0.86 & 0.81 & 0.79 & 143
\end{tabular}


International Journal of Management, IT \& Engineering

Vol. 11 Issue 06, June 2021

ISSN: 2249-0558 Impact Factor: 7.119

Journal Homepage: http://www.ijmra.us, Email: editorijmie@gmail.com

Double-Blind Peer Reviewed Refereed Open Access International Journal - Included in the International Serial Directories Indexed \& Listed at:

Ulrich's Periodicals Directory @, U.S.A., Open J-Gate as well as in Cabell's Directories of Publishing Opportunities, U.S.A

\section{Probit and Logit results.}

Table 2. Binary Probit model results

Dependent Variable: BUDGETSUCCESS

Method: ML - Binary Probit (Newton-Raphson / Marquardt steps)

Sample: 1569

Included observations: 569

Convergence achieved after 8 iterations

Coefficient covariance computed using observed Hessian

Variable Coefficient Std. Error z-Statistic Prob.

$\begin{array}{lllll}\text { COMMUNICATION } & 0.220766 & 0.031644 & 6.976508 & 0.0000 \\ \text { CONTROL } & 0.790542 & 0.080802 & 9.783694 & 0.0000 \\ \text { COORDINATION } & 0.837952 & 0.104648 & 8.007339 & 0.0000 \\ \text { MOTIVATION } & 0.004380 & 0.003777 & 1.159535 & 0.2462 \\ \text { PARTICIPATION } & 0.008043 & 0.003605 & 2.231406 & 0.0257 \\ \text { C } & 24.68135 & 2.449692 & 10.07529 & 0.0000\end{array}$

McFadden R-squared

0.759582

Mean dependent var

0.627417

S.D. dependent var

0.483918

S.E. of regression

0.224082

Akaike info criterion

0.338593

Sum squared resid

28.26975

Schwarz criterion

0.384398

Log likelihood

$-90.32972$

Hannan-Quinn criter.

0.356466

Deviance

180.6594

Restr. deviance

751.4400

Restr. log likelihood

$-375.7200$

LR statistic

570.7806

Avg. log likelihood

$-0.158752$

Prob(LR statistic)

0.000000

Obs with Dep $=0$

Obs with Dep $=1$ 
International Journal of Management, IT \& Engineering

Vol. 11 Issue 06, June 2021

ISSN: 2249-0558 Impact Factor: 7.119

Journal Homepage: http://www.ijmra.us, Email: editorijmie@gmail.com

Double-Blind Peer Reviewed Refereed Open Access International Journal - Included in the International Serial Directories Indexed \& Listed at:

Ulrich's Periodicals Directory @, U.S.A., Open J-Gate as well as in Cabell's Directories of Publishing Opportunities, U.S.A

The results from Probit and Logit models are reported in Table 2. The results show that all of the features, in both models, except motivation have significant impact on the probability of success. The features such as control and coordination have fairly large coefficients. This means that these two variables are the most crucial factors of success for a project-budget. McFadden R-square, 0.75, in both models shows that the models fit.

Table 3. Binary Logit model results

Dependent Variable: BUDGETSUCCESS

Method: ML - Binary Logit (Newton-Raphson / Marquardt steps)

Sample: 1569

Included observations: 569

Convergence achieved after 10 iterations

Coefficient covariance computed using observed Hessian

Variable Coefficient Std. Error z-Statistic Prob.

$\begin{array}{lllll}\text { COMMUNICATION } & 0.398387 & 0.059233 & 6.725756 & 0.0000 \\ \text { CONTROL } & 1.423935 & 0.157747 & 9.026688 & 0.0000 \\ \text { COORDINATION } & 1.500841 & 0.196456 & 7.639574 & 0.0000 \\ \text { MOTIVATION } & 0.006390 & 0.006783 & 0.942100 & 0.3461 \\ \text { PARTICIPATION } & 0.013661 & 0.006437 & 2.122207 & 0.0338 \\ \text { C } & 44.30873 & 4.763252 & 9.302200 & 0.0000\end{array}$

McFadden R-squared 0.758082

S.D. dependent var

0.483918

Akaike info criterion

0.340574

Schwarz criterion

0.386379

Hannan-Quinn criter. 0.358447

Restr. deviance $\quad 751.4400$

LR statistic

569.6534

Prob(LR statistic)

0.000000
Mean dependent var

0.627417

S.E. of regression

0.223541

Sum squared resid

28.13354

Log likelihood

$-90.89328$

Deviance

181.7866

Restr. log likelihood

$-375.7200$

Avg. $\log$ likelihood

$-0.159742$
Obs with Dep $=0$

Obs with Dep $=1$
212

357
Total obs

569 


\section{Conclusion}

This study determined empirically the factors that contribute to a budget's success. To determine this, this study used three distinct supervised machine learning algorithms for classification: Support Vector Machine (SVM), Logistic regression, and Probit regression on 470 projects.

A method based on SVM in kernel mode achieved 81 percent accuracy with acceptable true positive and false negative rates, indicating that it is effective when used to predict project budget success. Several other approaches exist, including Naive Bayes, decision trees, and neural networks. However, when the dataset used in this work is compared to the methods listed above, the SVM has higher accuracy.

The results of Probit and Logit models show that all of the features/determinants in both models, except motivation, have a significant impact on the probability of success. The features such as control and coordination have fairly large coefficients. This means that these two variables are the most crucial factors of success for a project budget.

\section{References}

Ahrens, Thomas, Laurence Ferry, and Rihab Khalifa. 2018. "The Hybridising of Financial and Service Expertise in English Local Authority Budget Control: A Practice Perspective." Qualitative Research in Accounting \& Management 15 (3): 341-57.

Binkele-Raible, Daniel, and Henning Fernau. 2010. "Enumerate and Measure: Improving Parameter Budget Management." In Parameterized and Exact Computation, 38-49. Springer Berlin Heidelberg.

Blomquist, Glenn C., Michael A. Newsome, and D. Brad Stone. 2003. "Measuring Principals' Values for Environmental Budget Management: An Exploratory Study." Journal of Environmental Management 68 (1): 83-93.

Caesarendra, Wahyu, Achmad Widodo, and Bo-Suk Yang. 2010. "Application of Relevance Vector Machine and Logistic Regression for Machine Degradation Assessment.” Mechanical Systems and Signal Processing 24 (4): 1161-71.

Callahan, Kevin R., Gary S. Stetz, and Lynne M. Brooks. 2011. Project Management Accounting: Budgeting, Tracking, and Reporting Costs and Profitability. Vol. 565. John Wiley \& Sons.

Greenberg, Penelope Sue; Greenberg. 2006. "Who Needs Budgets? You Do.” Montvale 88 (2): $40-45$.

Harrison, Frederick, and Dennis Lock. 2017. Advanced Project Management: A Structured Approach. Routledge.

Hofstede, G. H. 1970. “The Game of Budget Control.” Operational Research Quarterly 21 (1): 
International Journal of Management, IT \& Engineering

Vol. 11 Issue 06, June 2021

ISSN: 2249-0558 Impact Factor: 7.119

Journal Homepage: http://www.ijmra.us, Email: editorijmie@gmail.com

Double-Blind Peer Reviewed Refereed Open Access International Journal - Included in the International Serial Directories Indexed \& Listed at:

Ulrich's Periodicals Directory @, U.S.A., Open J-Gate as well as in Cabell's Directories of Publishing Opportunities, U.S.A

\section{5.}

Musa, Abdallah Bashir. 2013. "Comparative Study on Classification Performance between Support Vector Machine and Logistic Regression.” International Journal of Machine Learning and Cybernetics 4 (1): 13-24.

Noble, W. S. 2006. "What Is a Support Vector Machine?" Nature Biotechnology. https://www.nature.com/articles/nbt1206-1565.

Parker, Robert J., and Larissa Kyj. 2006. "Vertical Information Sharing in the Budgeting Process.” Accounting, Organizations and Society 31 (1): $27-45$.

Rickards, Robert C. 2006. "Beyond Budgeting: Boon or Boondoggle?" Investment Management and Financial Innovations, no. 3, Iss. 2: 62-76.

Roberts, Paul. 2011. Effective Project Management: Identify and Manage Risks Plan and Budget Keep Projects under Control. Kogan Page Publishers.

Shim, J. K., J. G. Siegel, and A. I. Shim. 2011. "Budgeting Basics and beyond." https://books.google.com/books?hl=en\&lr=\&id=FsioDgAAQBAJ\&oi=fnd\&pg=PR11\&dq=bud geting\&ots=qQAimc_6nr\&sig=WyD1Qnpt5GMMlg_suWGYMV1VuBw.

Taylor, Audrey G; Rafai. 2003. "Strategic Budgeting: A Case Study and Proposed Framework." Montvale 5 (1): 1.

Ukil, Abhisek. 2007. "Support Vector Machine.” In Intelligent Systems and Signal Processing in Power Engineering, edited by Abhisek Ukil, 161-226. Berlin, Heidelberg: Springer Berlin Heidelberg.

White, Diana, and Joyce Fortune. 2002. "Current Practice in Project Management - an Empirical Study.” International Journal of Project Management 20 (1): 1-11.

Wong-On-Wing, Bernard, Lan Guo, and Gladie Lui. 2010. "Intrinsic and Extrinsic Motivation and Participation in Budgeting: Antecedents and Consequences." Behavioral Research in Accounting 22 (2): 133-53.

Zhu, Ji, and Trevor Hastie. 2005. "Kernel Logistic Regression and the Import Vector Machine." Journal of Computational and Graphical Statistics: A Joint Publication of American Statistical Association, Institute of Mathematical Statistics, Interface Foundation of North America 14 (1): 185-205. 